\title{
Clinical efficacy of external beam radiotherapy complementing incomplete transarterial chemoembolization for hepatocellular carcinoma
}

\author{
Sunmin Park, Won Sup Yoon, Mi Hee Jang, Chai Hong Rim \\ Department of Radiation Oncology, Korea University Ansan Hospital, Gyeong-Gi Do, \\ Republic of Korea
}

Corresponding author: Chai Hong Rim, MD, Department of Radiation Oncology, Ansan Hospital, Korea University, 123 Jeokgeum-ro, Danwon-gu, Ansan, Gyeonggi-do, 15355, Republic of Korea, Tel.: 82-31-412-6850; FAX: 82-31-412-6850; Email:

crusion3@naver.com

Biographical note:

Sunmin Park is a radiation oncology specialist and a clinical instructor at the Korea University Medical College, who performed data curation and major drafting of this study.

Won Sup Yoon is a head of the Radiation Oncology Department at Korea University Ansan Hospital. He published a number of studies regarding radiotherapy for breast cancer, liver cancer, and also dosimetry of radiotherapy. He supervised the manuscript and advised with his expertise and clinical experiences

Mi Hee Jang is a research nurse who performed main data recruitment and curation of the present study

Chai Hong Rim is a radiation oncologist and a passionate researcher who has published more than 30 articles as a primary or corresponding author in recent 3 years, including 11 articles about radiotherapy for hepatocellular carcinoma. He has also academic expertise in treating lung cancer, meta-analysis, and prevention oncology. 


\section{Abstract}

Purpose: External beam radiotherapy (EBRT) has been commonly applied as salvage or a combination locoregional modality after transarterial chemoembolization (TACE) for hepatocellular carcinomas (HCCs). This study reports oncologic outcomes and feasibility after application of the two modalities in our center.

Methods: Forty consecutive patients who underwent EBRT due to incomplete responses of TACE were evaluated. Fourteen patients (35.0\%) received stereotactic body radiotherapy (SBRT) and the remaining patients received conventionally fractionated radiotherapy (RT). A majority of patients who underwent SBRT received doses of 27 to 48 Gy in 3-4 fractions (median ${ }^{*} \mathrm{EQD}_{2}: 57.0 \mathrm{~Gy}$ ). Conventionally fractionated RT was performed with a median $\mathrm{EQD}_{2}$ of $47.8 \mathrm{~Gy}$.

Results: The median follow-up duration was 14.4 months (range: 2.6-83.0 months). A majority $(77.5 \%)$ of patients were regarded as having Child-Pugh grade A. The median tumor size was $3.4 \mathrm{~cm}$ (range: $0.8-20.1 \mathrm{~cm}$ ). Ten patients $(25.0 \%)$ had thrombosis at a main portal branch. The 1- and 2-year overall survival (OS) and progression-free survival (PFS) rates were $82.2 \%$ and $42.1 \%$ and $55.8 \%$ and $32.1 \%$, respectively. The local control rates were $89.1 \%$ and $89.1 \%$ at 1 and 2 years, respectively. The albumin level was a significant factor affecting OS $(p=0.002)$, and the BCLC stage significantly affected PFS $(p=0.001)$. Intrahepatic, out-of-field recurrence was the main cause of disease progression $(60.0 \%)$, and distant metastasis developed in 12 patients (30.0\%) during follow-up. Non-classic radiation-induced liver disease was seen in five (12.5\%) patients, and two (5\%) patients experienced grade $\geq 3$ hepatic toxicities.

\section{Conclusions:}

EBRT after incomplete TACE was feasible and yielded favorable oncologic outcomes. However, disease progression related to intrahepatic failure remained a hindrance.

*EQD2: Equivalent dose in 2 Gy per fraction radiotherapy

Keywords: hepatocellular carcinoma; liver neoplasm; transarterial chemoembolization; external beam radiotherapy; stereotactic body radiation therapy 
medRxiv preprint doi: https://doi.org/10.1101/2020.09.20.20197285; this version posted September 23, 2020. The copyright holder for this

\section{Introduction}

Transarterial chemoembolization (TACE) is clinically the most commonly applied locoregional treatment for hepatocellular carcinoma (HCC) (Park et al. 2015; Raoul et al. 2011). Given the established overall survival (OS) gain for patients with unresectable HCCs (Llovet et al. 2002; Lo et al. 2002), TACE has been solely recommended for intermediate stage cases in the Barcelona Clinic of Liver Cancer system (EASL 2018) and has been suggested as a primary locoregional modality for inoperable HCCs in many international guidelines (KLCA 2019; NCCN. 2020; S. Park et al. 2020).

The limitation of TACE is that complete remission and sustained local control is difficult to achieve, except for early HCCs such as single and small tumors $(\leq 3 \mathrm{~cm})$ (Henry et al. 2013; J. H. Shim et al. 2010). In a recent meta-analysis by Lencioni et al (Lencioni et al. 2016), progression-free survival (PFS) after TACE for HCCs was as mediocre as $24 \%$ at 2 years, and the majority of lesions progressed in a year.

External beam radiation therapy (EBRT) has been increasingly applied for $\mathrm{HCC}$, as CT-based planning has enabled selective tumor irradiation while sparing normal liver (Rim and Yoon 2018). EBRT is advantageously performed regardless of tumor location and can be applied to tumors with locations where RFA is difficult to apply (e.g., tumors near major vessels or the diaphragm) (J. Lee et al. 2020; Rim et al. 2019). While standard salvage or complementing options after incomplete TACE have yet to be established, EBRT has been applied for these purposes in real-world experiences (Choi et al. 2014; Kang et al. 2012; Kim et al. 2006; Oh et al. 2010; S. J. Shim et al. 2005; Zhong et al. 2014).

This study aimed to report the clinical experience in our center, a middle-sized tertiary hospital in South Korea, in performing EBRT for HCCs to complement or salvage incomplete TACE. Related literature and suggestions for future treatment and research have also been discussed. 
medRxiv preprint doi: https://doi.org/10.1101/2020.09.20.20197285; this version posted September 23, 2020. The copyright holder for this

\section{Methods}

\section{Patients recruitment and evaluation}

A chart review was performed for HCC patients who underwent external radiation therapy (RT) between March 2010 and May 2019 (IRB number: 2020AS0076). Inclusion criteria were: 1) an initial diagnosis of primary $\mathrm{HCC}$ or recurrence; 2) an incomplete response after TACE (e.g., remnant viable lesion present or inadequate lipiodol uptake in the tumor; 3 ) age 18 years; 4) Child-Pugh (CP) class A or B; 5) $\geq 25$ Gy of radiation dose; and 6) no evidence of uncontrolled lesions at any other sites than primary liver. Oncologic outcomes including survival outcomes, tumor response, and local control were evaluated. Tumor response was assessed using the Modified Response Evaluation Criteria in Solid Tumors (mRECIST) (Lencioni and Llovet 2010). We included patients who had undergone conventional fractionated RT and stereotactic body radiation therapy (SBRT). Complications related to RT were evaluated according to the Common Terminology Criteria for Adverse Events (CTCAE; version 4.03). Non-classic radiation-induced liver disease (RILD) was defined as elevated liver transaminase levels more than five times the upper normal limit or CP score worsening by $\geq 2$ within 3 months after RT. Local control was defined as no new lesion or no increase in the tumor size in the treated area (in-field failure). Intrahepatic recurrence was defined as the development of a new lesion outside the treated area, but within the liver (out-of-field failure). Disease progression was defined as the development of intrahepatic recurrence and/or distant recurrence at any site outside of the liver. Overall survival, PFS, and recurrence-free survival (RFS) were estimated from the start date of RT to the date of death, the last follow-up examination, or to the date of tumor progression and recurrence, respectively. All patients had follow-ups at 3- or 6-months intervals after treatment. At each follow-up, a detailed questionnaire on clinical status and physical 
medRxiv preprint doi: https://doi.org/10.1101/2020.09.20.20197285; this version posted September 23, 2020. The copyright holder for this

examination were administered and liver magnetic resonance imaging (MRI) or dynamic computed tomography (LDCT) were performed.

\section{Statistics}

The Kaplan-Meier method was used to evaluate the probability of cumulative survival. Univariate and multivariate Cox proportional hazards models were used to evaluate the association of variables with survival outcomes and local control. The backward elimination method was used to select the principal factors in multivariate analyses. Univariate logistic regression analysis was performed to compare clinical parameters for non-classic RILD. Statistical Package for the Social Sciences version 21.0 were used for all statistical analyses (IBM Corp., Armonk, NY, USA).

\section{Radiotherapy procedure}

CT simulation was performed using a Philips Brilliance Big Bore CT (Philips Healthcare, Cleveland, OH, USA). A compression belt was applied at the mid-abdomen of the patients who were lying on the Body Pro-Lok ${ }^{\mathrm{TM}}$ (Body Pro-Lok, CIVCO, USA) in a supine position. The patients were immobilized using Vac-L ok (KIKWANG MEDICAL, KOREA) and wing board (CIVCO, USA). Four-dimensional CT (4DCT) was scanned to a slice thickness of 2-3 mm using the Varian RPM system (Varian Medical Systems, Palo Alto, CA) to monitor and record a respiratory signal, specifically the rise and fall of the anterior abdominal surface. A 4DCT image was taken while abdominal compression was performed. After scanning, the 4DCT image data sets were sorted into 10 phases such that the $0 \%$ respiratory phase corresponds to peak inhalation and the $50 \%$ phase to peak exhalation. A total of 10 phases are evenly distributed throughout the respiratory cycle. The GTV can consist of the entire HCC or part of the HCC and vascular invasion at the discretion of the investigator. The GTV was contoured in the CT equating to the $50 \%$ phase, and the internal target volume (ITV) was set to be expanded by reflecting the movement in all phases. 
medRxiv preprint doi: https://doi.org/10.1101/2020.09.20.20197285; this version posted September 23, 2020. The copyright holder for this

Planning target volume (PTV) was set with a margin of 5-7 mm from ITV. Dose constraints to organs at risk (OAR), including the duodenum, liver, spinal cord, and esophagus, were adopted according to the Quantitative Analyses of Normal Tissue Effects in the Clinic (QUANTEC) (Bentzen et al. 2010). In case of SBRT, a dose was prescribed to an isodose covering at least $95 \%$ of the PTV. If OAR constraints are not met, then the $95 \%$ isodose was relaxed or the total dose was reduced according to the clinicians' discretion. The dose maximum within the PTV was preferably were between $110 \%$ and $140 \%$ of the prescribed dose. For IMRT, the target dose was prescribed to the PTV more than $95 \%$ of the prescribed dose to at least $95 \%$ of the PTV. For 3DCRT planning, 3-5 portal beams with planar or noncoplanar arrangement were used. Dosimetric margins around the PTV were selected so that the $80 \%$ isodose line encompasses $100 \%$ of the PTV. In addition, PTV received $95 \%-107 \%$ of the prescribed total dose. The biologically effective dose (BED) and equivalent dose in 2 Gy per fraction radiotherapy (EQD2) were calculated from the prescription dose using $\alpha / \beta$ ratio of 10. Gating during treatment was not performed because ITV reflected movements of all phases in free breathing. The setup was performed using a tattoo applied to the patient, and daily pre-treatment cone-beam computed tomography (CBCT) matching was verified by a physician. Image guidance was performed by matching the liver contour and lipiodolized GTV as fiducial. If matching was satisfactory, then treatment was performed after applying the couch shift.

\section{Results}

\section{Patient characteristics}

Between March 2010 and May 2019, 44 patients were treated with RT due to incomplete response of TACE. Of them, 40 patients (46 lesions) met all the enrollment 
medRxiv preprint doi: https://doi.org/10.1101/2020.09.20.20197285; this version posted September 23, 2020. The copyright holder for this

criteria and were included in this analysis. Most patients were males (82.5\%). Median age was 60 years (range, 43.0-77.0 years) at the initiation of RT. The longest diameter of the tumors was $0.8-20.1 \mathrm{~cm}$, with median value of $3.42 \mathrm{~cm}$. The tumor volume was $4.0-1939.4$ $\mathrm{cm}^{3}$, with median value of $94.1 \mathrm{~cm}^{3}$. A majority $(77.5 \%)$ of patients were regarded as having $\mathrm{CP}$ class $\mathrm{A}$, and the remaining were regarded as having CP class B. Ten patients $(25.0 \%)$ had thrombosis at a main portal branch and two patients (5.0\%) in a segmental branch. Patients had undergone conventionally fractionated RT with doses of 25-65 Gy (median EQD2: 47.8 Gy) in 8-27 fractions. SBRT was performed with doses of 27-48 Gy (median EQD2: 57.0 Gy) in 3-4 fractions (Table 1). Thirteen of 40 patients (32.5\%) received systemic chemotherapy (sorafenib and regorafenib) during the entire follow-up period. None of the 13 patients received systemic therapies simultaneously with RT; all received these after completion of RT.

\section{Survival analysis}

The median follow-up duration was 14.4 months (range, 2.6-83.0 months) for all patients, and 23 of the 40 patients survived during the follow-up period. The median OS was 15.0 months (range, 2.6-100.6 months). The 1- and 2-year OS rates were $82.2 \%$ and $55.8 \%$, respectively (Figure 1). The 1- and 2-year PFS rates were $42.1 \%$ and 32.1\% (Figure 1), respectively. For OS, the albumin level was the sole significant factor in both univariate and multivariate analyses ( $p=0.002$ in multivariate analysis, Table 2$)$. The BCLC stage was the only significant prognostic factor ( $p=0.006$ in multivariate analysis) for PFS in both univariate and multivariate analysis (Table 3).

Tumor response and local control rate

In-field (target lesion) complete remission (CR) and partial response (PR) rates were $37.0 \%$ and $41.3 \%$, respectively. Four patients (8.7\%) were PD and six (13.0\%) were SD.

Overall in-field response (CR and PR) rate was 78.3\%. The 1- and 2-year local control (LC) 
medRxiv preprint doi: https://doi.org/10.1101/2020.09.20.20197285; this version posted September 23, 2020. The copyright holder for this

rates were $89.1 \%$ and $89.1 \%$, respectively (Figure 1). For LC, the tumor type (nodular/multinodular/infiltrative) was a statistically significant factor in the univariate analysis $(p=0.02)$ and had borderline significance in the multivariate analysis $(p=0.077)$. The 1- and 2-year intrahepatic recurrence free survival (IHRFS) rates were $41.5 \%$ and $34.2 \%$, respectively. The univariate and multivariate analyses revealed that the BCLC stage was the only significant factor for IHRFS ( $p=0.003$, and $p=0.003$, respectively. Figure 1$)$.

\section{Patterns of failure}

Overall, 26 patients $(65.0 \%)$ had treatment failures. Local failure (in-field failure) occurred in 5 of 46 lesions in four patients $(10.0 \%)$. Intrahepatic out of-field failure was observed in 24 patients $(60.0 \%)$, and distant failure (extrahepatic metastasis) occurred in 12 patients (30.0\%) (Figure 2). The most common site for distant failure was the lungs, followed by the lymph nodes and bones.

\section{Treatment-related toxicities}

All patients received planned RT without any interruptions due to intolerable side effects. No classic RILD was observed. Non-classic RILD was seen in five (12.5\%) patients. Elevation of liver transaminase levels by more than five times was observed in two $(5.0 \%)$ patients within 3 months after RT (Grade $\geq 3$ hepatic toxicities; grade 3: one patient, grade 4: one patient). Two patients who experienced grade $\geq 3$ hepatic toxicities improved spontaneously with conservative treatment. Three $(7.5 \%)$ patients showed elevation in the CP score of $\geq 2$. Of the five patients who experienced non-classic RILD, two underwent SBRT, two underwent 3DCRT, and one underwent intensity modulated radiotherapy (IMRT). In these patients, the median mean liver dose (MLD) was 13.3 Gy (range, 7.9-29.8 Gy) and the CP score was 6 (5-8) points. In the univariate analysis, none of the major clinical parameters were associated with non-classic RILD (Supplementary Table 1). Two patients experienced grade 3 thrombocytopenia (Table 4). One patient experienced diminution of platelet count to 
medRxiv preprint doi: https://doi.org/10.1101/2020.09.20.20197285; this version posted September 23, 2020. The copyright holder for this

20,000/ul after RT due to esophageal variceal bleeding, but this normalized after platelet concentrate transfusion and esophageal variceal ligation. The other patient, however, developed HCC rupture 2 months after RT and 1 month after consequent TACE, showing grade 3 thrombocytopenia with hemoperitoneum. After conservative care including transfusion, thrombocytopenia stabilized, but 3 weeks after HCC rupture, the patient died of asphyxia after vomiting. Severe gastrointestinal complications such as bleeding or perforation were not reported during the follow-up period.

\section{Discussion}

The study results demonstrate that application of EBRT after incomplete TACE can confer a favorable response and sustained in-field tumor control. A majority of complications were transient and mild, and serious toxicity (e.g., grade $\geq 3$ ) was rare. Prognostic factors, including the albumin level and BCLC stage affecting the OS and PFS, were correlated with known HCC biology and previous studies (Klein and Dawson 2013); the albumin level can reflect not only the nutritional status but also the liver function and is an independent prognostic factor of oncologic outcomes (Bağırsakçı et al. 2017; Liu et al. 2017; Wu et al. 2019).

Considering the result of our study and the previous literature, in-field local control was mostly favorable after incomplete TACE (Table 5) (Chiang et al. 2019; Chihwan. Choi et al. 2014; Jacob et al. 2015; Kang et al. 2012; Kibe et al. 2020; Kim et al. 2006; Oh et al. 2010; S. J. Shim et al. 2005; Zhong et al. 2014). Although the study by Choi et al (Chihwan. Choi et al. 2014). Reported a relatively high in-field failure rate, high incidences of infiltrative or multinodular tumor type (80\%) and BCLC C patients $(45 \%)$ might have affected the result. Since the subject of literature is a salvage setting, many of the referenced 
medRxiv preprint doi: https://doi.org/10.1101/2020.09.20.20197285; this version posted September 23, 2020. The copyright holder for this

studies involved a portion of patients with relatively large tumor or portal vein thrombosis. A majority of studies prescribed a dose of around 40-60 Gy in EQD2 ${ }_{10 \mathrm{~Gy}}$ in both SBRT and conventional schemes, indicating a difficulty in aggressive dose escalation. In the studies by Jacob et al. (Jacob et al. 2015) and Kang et al. (Kang et al. 2012), high-dose SBRT achieved good local control. However, considering that locally advanced cases are commonly involved and that $\mathrm{HCC}$ has a relatively high $\alpha / \beta$ ratio, which is benefited by the fractionated scheme ( 15Gy) (Tai et al. 2008), conventionally or moderately fractionated RT could be also suitable options reflected by favorable in-field control in studies including ours.

Out-of-field intrahepatic metastases were burdensome in most of the studies, including the present one and approximately ranged from 405 to $60 \%$. Such a result sheds light on the role of systemic treatment; however, literature regarding the concomitant use of systemic treatment and EBRT for HCC is still scarce. In a phase 2 study of combined sorafenib and EBRT for HCC, oncologic efficacy was moderately favorable (2-year OS: $32 \%$, response rate: 55\%), but intrahepatic out-of-field progression was still problematic (30\%) (Chen et al. 2014). In a comparative study by Wada et al. (Wada et al. 2018), combined use of sorafenib and EBRT showed a comparable toxicity rate to sorafenib alone, but the 2-year PFS was $<40 \%$.

Intrahepatic progression has been deemed one of the most difficult challenges regarding HCC treatment. Additional studies are still necessary, but there are several promising scenarios. Preclinical evidence of synergistic effects whereby EBRT affects tumor microenvironments, enhancing the effects of immune checkpoint inhibitors, has emerged (Choi et al. 2019). Recently, the combined application of anti-VEGF and an immune checkpoint inhibitor demonstrated significantly superior oncologic outcomes to sorafenib (Finn et al. 2020). Nivolumab also showed promising results in its phase $1 / 2$ trials for advanced HCCs; the response rate was $20 \%$ and the median duration of response was 9.9 
medRxiv preprint doi: https://doi.org/10.1101/2020.09.20.20197285; this version posted September 23, 2020. The copyright holder for this

months (Melero et al. 2017). Several trials of combined treatment of EBRT and immune checkpoint inhibitors (NCT0382102, NCT03203304, NCT0331672) are ongoing, from which contributions to reduce intrahepatic progression are expected. In addition, surgical conversion after EBRT combined with arterial directed therapy might yield excellent outcomes. In a series reported from a Korean tertiary center, although the conversion rate to surgery was $<20 \%$, the median OS of patients who underwent conversion surgery after EBRT exceeded 5 years (Byun et al. 2019; H. S. Lee et al. 2014). Therefore, consequent surgical resection, which might prevent further hepatic progression, might be considered for favorable responders after EBRT.

In addition to perspectives of numerical oncologic outcomes, EBRT is a practical and feasible option for locally advanced HCCs for which other locoregional modalities are difficult to apply for anatomical reasons. We selected two cases showing significant improvements initially referred as intractable cases. The case depicted in Figure 3 upper showed complete remission after EBRT for infiltrative HCC involving a major vessel and the middle portion between the bilateral lobes, which is deemed very difficult for the application of any locoregional modalities. The case in Figure 3 lower shows an impressive response to EBRT for a huge tumor for which previous TACE was not very efficacious and that subsequent TACE had greater effects inside the tumor (hypovasculated with necrosis) partly due to vasculature remodeling after EBRT (Castle and Kirsch 2019; El Kaffas et al. 2013).

Our study has some limitations, including its retrospective design and the small number of patients and clinical heterogeneity. These limitations are shared by several other studies with correlated subjects. The number of patients included in future studies should be increased through means such as multi-center recruitment, consequently enabling more specific studies with less heterogeneous subgroups. As mentioned earlier, studies regarding a 
medRxiv preprint doi: https://doi.org/10.1101/2020.09.20.20197285; this version posted September 23, 2020. The copyright holder for this preprint (which was not certified by peer review) is the author/funder, who has granted medRxiv a license to display the preprint in perpetuity. All rights reserved. No reuse allowed without permission.

combined treatment of EBRT and immune checkpoint inhibitors and consequent resection for favorable responders are strongly warranted.

\section{Conclusion}

EBRT after incomplete TACE is a feasible option yielding favorable tumor response and sustained local control. However, intrahepatic progression remains a hindrance conferring a mediocre level of survival. Future studies should be undertaken to prevent intrahepatic progression, investigating combined treatment with novel systemic treatment and consequent surgical resection of favorable responders of EBRT. 
medRxiv preprint doi: https://doi.org/10.1101/2020.09.20.20197285; this version posted September 23, 2020. The copyright holder for this preprint (which was not certified by peer review) is the author/funder, who has granted medRxiv a license to display the preprint in perpetuity. All rights reserved. No reuse allowed without permission.

\section{Acknowledgement}

This study is supported by National Research Fund of Korea (NRF-

2019M2D2A1A01031560).

\section{Declaration of Interest}

No potential conflict of interest was reported by the authors.

\section{Ethical approval and informed consent}

Our study is evaluated and approved by the Institutional Review Board of Korea

University Medical Center (IRB number: 2020AS0076), and informed consent was waived because our study did not pose any harm to the patients involved and no personally

identifiable information was used. References: see the journal's instructions for authors for details on style 


\section{References}

Bağırsakçı E, Şahin E, Atabey N, Erdal E, Guerra V, Carr BI. 2017. Role of albumin in growth inhibition in hepatocellular carcinoma. Oncology. 93(2):136-142.

Bentzen SM, Constine LS, Deasy JO, Eisbruch A, Jackson A, Marks LB, Ten Haken RK, Yorke ED. 2010. Quantitative Analyses of Normal Tissue Effects in the Clinic (QUANTEC): an introduction to the scientific issues. Int J Radiat Biol Phys. 76(3):S3-S9.

Byun HK, Kim HJ, Im YR, Han K-H, Seong J. 2019. Dose escalation by intensity modulated radiotherapy in liver-directed concurrent chemoradiotherapy for locally advanced BCLC stage C hepatocellular carcinoma. Radiother Oncol. 133:1-8.

Castle KD, Kirsch DG. 2019. Establishing the impact of vascular damage on tumor response to high-Dose radiation therapy. Cancer Res. 79(22):5685-5692.

Chen S-W, Lin L-C, Kuo Y-C, Liang J-A, Kuo C-C, Chiou J-F. 2014. Phase 2 study of combined sorafenib and radiation therapy in patients with advanced hepatocellular carcinoma. Int J Radiat Biol Phys. 88(5):1041-1047.

Chiang CL, Chan MKH, Yeung CSY, Ho CHM, Lee FAS, Lee VWY, Wong FCS, Blanck O. 2019. Combined stereotactic body radiotherapy and trans-arterial chemoembolization as initial treatment in BCLC stage B-C hepatocellular carcinoma. Strahlentherapie und Onkologie: Organ der Deutschen Rontgengesellschaft [et al]. 195(3):254-264.

Choi C, Koom WS, Kim TH, Yoon SM, Kim JH, Lee H-S, Nam T-K, Seong J. 2014. A prospective phase 2 multicenter study for the efficacy of radiation therapy following incomplete transarterial chemoembolization in unresectable hepatocellular carcinoma. Int $\mathbf{J}$ Radiat Biol Phys. 90(5):1051-1060.

Choi C, Yoo GS, Cho WK, Park HC. 2019. Optimizing radiotherapy with immune checkpoint blockade in hepatocellular carcinoma. World J Gastroenterol. 25(20):2416.

EASL. 2018. EASL clinical practice guidelines: management of hepatocellular carcinoma. $\mathbf{J}$ Hepatol. 69(1):182-236. 
medRxiv preprint doi: https://doi.org/10.1101/2020.09.20.20197285; this version posted September 23, 2020. The copyright holder for this

El Kaffas A, Giles A, Czarnota GJ. 2013. Dose-dependent response of tumor vasculature to radiation therapy in combination with Sunitinib depicted by three-dimensional highfrequency power Doppler ultrasound. Angiogenesis. 16(2):443-454.

Finn RS, Qin S, Ikeda M, Galle PR, Ducreux M, Kim TY, Kudo M, Breder V, Merle P, Kaseb AO, et al. 2020. Atezolizumab plus Bevacizumab in Unresectable Hepatocellular Carcinoma. The New England journal of medicine. 382(20):1894-1905.

Henry JC, Malhotra L, Khabiri H, Guy G, Michaels A, Hanje J, Azevedo M, Bloomston M, Schmidt CR. 2013. Best radiological response to trans $\square$ arterial chemoembolization for hepatocellular carcinoma does not imply better outcomes. HPB. 15(3):196-202.

Jacob R, Turley F, Redden DT, Saddekni S, Aal AK, Keene K, Yang E, Zarzour J, Bolus D, Smith JK, et al. 2015. Adjuvant stereotactic body radiotherapy following transarterial chemoembolization in patients with non-resectable hepatocellular carcinoma tumours of $\geq 3$ $\mathrm{cm}$. HPB : the official journal of the International Hepato Pancreato Biliary Association. 17(2):140-149.

Kang JK, Kim MS, Cho CK, Yang KM, Yoo HJ, Kim JH, Bae SH, Jung DH, Kim KB, Lee DH. 2012. Stereotactic body radiation therapy for inoperable hepatocellular carcinoma as a local salvage treatment after incomplete transarterial chemoembolization. Cancer. 118(21):5424-5431.

Kibe Y, Takeda A, Tsurugai Y, Eriguchi T. 2020. Local control by salvage stereotactic body radiotherapy for recurrent/residual hepatocellular carcinoma after other local therapies.

Acta Oncol. 1-7.

Kim TH, Kim DY, Park J-W, Kim YI, Kim SH, Park HS, Lee WJ, Park SJ, Hong EK, Kim C-M. 2006. Three-dimensional conformal radiotherapy of unresectable hepatocellular carcinoma patients for whom transcatheter arterial chemoembolization was ineffective or unsuitable. Amer J Clin Oncol. 29(6):568-575.

KLCA. 2019. 2018 Korean Liver Cancer Association-National Cancer Center Korea practice guidelines for the management of hepatocellular carcinoma. Kor J Radiol. 20(7):1042-1113. 
medRxiv preprint doi: https://doi.org/10.1101/2020.09.20.20197285; this version posted September 23, 2020. The copyright holder for this

Klein J, Dawson LA. 2013. Hepatocellular carcinoma radiation therapy: review of evidence and future opportunities. Int J Radiat Biol Phys. 87(1):22-32.

Lee HS, Choi GH, Choi JS, Kim KS, Han K-H, Seong J, Ahn SH, Park JY, Kim SU, Kim BK. 2014. Surgical resection after down-staging of locally advanced hepatocellular carcinoma by localized concurrent chemoradiotherapy. Ann Surg Oncol. 21(11):3646-3653.

Lee J, Shin IS, Yoon WS, Koom WS, Rim CH. 2020. Comparisons between radiofrequency ablation and stereotactic body radiotherapy for liver malignancies: Meta-analyses and a systematic review. Radiother Oncol. 145:63-70.

Lencioni R, de Baere T, Soulen MC, Rilling WS, Geschwind JFH. 2016. Lipiodol transarterial chemoembolization for hepatocellular carcinoma: a systematic review of efficacy and safety data. Hepatology. 64(1):106-116.

Lencioni R, Llovet JM. 2010. Modified RECIST (mRECIST) assessment for hepatocellular carcinoma. Semin Liver Dis. 30(1):52-60.

Liu PH, Hsu CY, Hsia CY, Lee YH, Chiou YY, Huang YH, Lee FY, Lin HC, Hou MC, Huo TI. 2017. ALBI and PALBI grade predict survival for HCC across treatment modalities and BCLC stages in the MELD Era. J Gastroenterol Hepatol. 32(4):879-886.

Llovet JM, Real MI, Montaña X, Planas R, Coll S, Aponte J, Ayuso C, Sala M, Muchart J, Solà R. 2002. Arterial embolisation or chemoembolisation versus symptomatic treatment in patients with unresectable hepatocellular carcinoma: a randomised controlled trial. Lancet. 359(9319):1734-1739.

Lo CM, Ngan H, Tso WK, Liu CL, Lam CM, Poon RTP, Fan ST, Wong J. 2002.

Randomized controlled trial of transarterial lipiodol chemoembolization for unresectable hepatocellular carcinoma. Hepatology. 35(5):1164-1171.

Melero I, Sangro B, Yau TC, Hsu C, Kudo M, Crocenzi TS, Kim T-Y, Choo S, Trojan J, Meyer T. 2017. Nivolumab dose escalation and expansion in patients with advanced hepatocellular carcinoma (HCC): The CheckMate 040 study. American Society of Clinical Oncology; p. 
NCCN. 2020. NCCN guidelines version 1. 2020, hepatobiliary cancers. Assessed March 1, 2020. Available at: https://www.nccn.org/professionals/physician_gls/pdf/hepatobiliary.pdf.

Oh D, Lim DH, Park HC, Paik SW, Koh KC, Lee JH, Choi MS, Yoo BC, Lim HK, Lee WJ. 2010. Early three-dimensional conformal radiotherapy for patients with unresectable hepatocellular carcinoma after incomplete transcatheter arterial chemoembolization: a prospective evaluation of efficacy and toxicity. Amer J Clin Oncol. 33(4):370-375.

Park JW, Chen M, Colombo M, Roberts LR, Schwartz M, Chen PJ, Kudo M, Johnson P, Wagner S, Orsini LS. 2015. Global patterns of hepatocellular carcinoma management from diagnosis to death: the BRIDGE Study. Liver Int. 35(9):2155-2166.

Park S, Yoon WS, Rim CH. 2020. Indications of external radiotherapy for hepatocellular carcinoma from updated clinical guidelines: Diverse global viewpoints. World $\mathbf{J}$

Gastroenterol. 26(4):393.

Raoul J-L, Sangro B, Forner A, Mazzaferro V, Piscaglia F, Bolondi L, Lencioni R. 2011. Evolving strategies for the management of intermediate-stage hepatocellular carcinoma: available evidence and expert opinion on the use of transarterial chemoembolization. Cancer Treat Rev. 37(3):212-220.

Rim CH, Yim HJ, Park S, Seong J. 2019. Recent clinical applications of external beam radiotherapy for hepatocellular carcinoma according to guidelines, major trials and metaanalyses. J Med Imaging Radiat Oncol. 63(6):812-821.

Rim CH, Yoon WS. 2018. Leaflet manual of external beam radiation therapy for hepatocellular carcinoma: a review of the indications, evidences, and clinical trials. Onco Targets Ther. 11:2865-2874.

Shim JH, Kim KM, Lee Y-J, Ko G-Y, Yoon H-K, Sung K-B, Park K-M, Lee S-G, Lim Y-S, Lee HC. 2010. Complete necrosis after transarterial chemoembolization could predict prolonged survival in patients with recurrent intrahepatic hepatocellular carcinoma after curative resection. Ann Surg Oncol. 17(3):869-877. 
medRxiv preprint doi: https://doi.org/10.1101/2020.09.20.20197285; this version posted September 23, 2020. The copyright holder for this preprint (which was not certified by peer review) is the author/funder, who has granted medRxiv a license to display the preprint in perpetuity. All rights reserved. No reuse allowed without permission.

Shim SJ, Seong J, Han KH, Chon CY, Suh CO, Lee JT. 2005. Local radiotherapy as a complement to incomplete transcatheter arterial chemoembolization in locally advanced hepatocellular carcinoma. Liver Int. 25(6):1189-1196.

Tai A, Erickson B, Khater KA, Li XA. 2008. Estimate of radiobiologic parameters from clinical data for biologically based treatment planning for liver irradiation. International journal of radiation oncology, biology, physics. 70(3):900-907.

Wada Y, Takami Y, Matsushima H, Tateishi M, Ryu T, Yoshitomi M, Matsumura T, Saitsu H. 2018. The safety and efficacy of combination therapy of sorafenib and radiotherapy for advanced hepatocellular carcinoma: a retrospective study. Int Med. 9826-9817.

Wu M-T, He S-Y, Chen S-L, Li L-F, He Z-Q, Zhu Y-Y, He X, Chen H. 2019. Clinical and prognostic implications of pretreatment albumin to $\mathrm{C}$-reactive protein ratio in patients with hepatocellular carcinoma. BMC cancer. 19(1):538.

Zhong NB, Lv GM, Chen ZH. 2014. Stereotactic body radiotherapy combined with transarterial chemoembolization for huge $(\geq 10 \mathrm{~cm})$ hepatocellular carcinomas: a clinical study. Mol Clin Oncol. 2(5):839-844. 
Table 1. Patient characteristics

Variables

Sex

Male

Female

Age (years)

Median (range)

BCLC

A

B

C

ECOG performance status

0

1

2

Child-Pugh Class

A

B

Viral Etiology

Hepatitis B virus

Hepatitis $\mathrm{C}$ virus

Non B, Non C

Alpha-fetoprotein (ng/mL)

Range

$\leq 200$

$>200$

Portal vein thrombosis

Yes, main branch

Yes, segmental branch

No

Number targets for RT

Single lesion

Two lesions

Four lesions

Tumor size $(\mathrm{cm})^{*}$
$37(90.2 \%)$

No. of patients (\%)

$(\mathrm{n}=40)$

$33(82.5 \%)$

$7(17.5 \%)$

$60(43-77)$

$9(22.5 \%)$

$12(30.0 \%)$

$19(47.5 \%)$

$13(32.5 \%)$

26 (65.0)

$1(2.5 \%)$

$31(77.5 \%)$

$9(22.5 \%)$

$25(62.5 \%)$

$6(15.0 \%)$

$9(22.5 \%)$

2-78209

29 (72.5\%)

$11(29.3 \%)$

$10(25.0 \%)$

2 (5\%)

$28(70 \%)$

$3(7.3 \%)$

$1(2.4 \%)$ 
Median (range)

$0.7-3.0$

$3.1-5.0$

$5.1-10.0$

$10.1-25.0$

Tumor volume $\left(\mathrm{cm}^{3}\right)^{*}$

Median (range)

Prior treatments

TACE only

TACE, RFA

TACE, PEI

TACE, RFA, PEI

TACE, RT

Resection, TACE

Resection, TACE, RFA

HAIC, RFA

HAIC, TACE, PEI

RT regimen*

Conventional fractionated RT

3DCRT

IMRT

\section{SBRT}

RT dose, median (range) ${ }^{*}$

EQD2

$\operatorname{BED}\left(\mathrm{Gy}_{10}\right)$

Treatment aim*

Palliative

Definitive
$3.4(0.8-20.1)$

$20(43.5 \%)$

$9(19.6 \%)$

$11(23.9 \%)$

$6(13.0 \%)$

$94.1(4.0-1939.4)$

18

12

1

1

1

4

2

1

1

$26(65.0 \%)$

$14(35.0 \%)$

$12(30.0 \%)$

$14(35.0 \%)$

$48.6(26.0-89.4)$

$58.3(31.3-107.3)$

$5(10.9 \%)$

$35(87.5 \%)$

\section{* Assessed for each lesion}

BCLC, Barcelona Clinic of Liver Cancer; ECOG, Eastern Cooperative Oncology Group; RT, radiotherapy; TACE, transarterial chemoembolization; HAIC, hepatic arterial infusion chemotherapy; RFA, radiofrequency ablation; PEI, percutaneous ethanol injection; 3DCRT, 3-dimensional conformal radiotherapy; IMRT, intensity modulated radiotherapy; SBRT, stereotactic body radiotherapy; EQD2, equivalent dose in 2Gy per fraction; $\mathrm{BED}$, biologically effective dose. 
Table 2. Predictive factors influencing overall survival

\begin{tabular}{|c|c|c|c|c|}
\hline \multirow[b]{2}{*}{ Variables } & \multicolumn{2}{|l|}{ Univariate analysis } & \multicolumn{2}{|l|}{ Multivariate analysis } \\
\hline & $\mathrm{HR}(95 \% \mathrm{CI})$ & $p$-value & $\operatorname{HR}(95 \% \mathrm{CI})$ & $\begin{array}{l}p \text { - } \\
\text { value }\end{array}$ \\
\hline Sex (male/female) & $1.341(0.432-4.166)$ & 0.612 & & \\
\hline Age & $0.959(0.912-1.010)$ & 0.112 & & \\
\hline $\operatorname{ECOG}(0-1 / 2)$ & $0.048(0.000-0.056)$ & 0.988 & & \\
\hline BCLC (A-B/C) & $2.651(1.005-6.994)$ & 0.043 & & \\
\hline Child-Pugh Class (A/B) & $\begin{array}{l}4.260(1.349- \\
13.452)\end{array}$ & 0.013 & & \\
\hline Albumin & $0.287(0.118-0.703)$ & 0.006 & $0.189(0.068-0.529)$ & 0.002 \\
\hline Bilirubin & $1.933(0.978-3.819)$ & 0.058 & & \\
\hline Tumor size & $1.077(0.986-1.176)$ & 0.099 & & \\
\hline Alpha-fetoprotein & $1.000(1.000-1.000)$ & 0.674 & & \\
\hline Viral etiology & & 0.782 & & \\
\hline $\mathrm{HBV}$ & 1 & & & \\
\hline $\mathrm{HCV}$ & $1.477(0.407-5.354)$ & & & \\
\hline NBNC & $0.855(0.238-3.078)$ & & & \\
\hline Total dose & $1.000(0.999-1.000)$ & 0.210 & & \\
\hline PVT (no/yes) & $1.963(0.665-5.797)$ & 0.222 & & \\
\hline Tumor type & & 0.946 & & \\
\hline Nodular & 1 & & & \\
\hline Multinodular & $1.149(0.317-4.164)$ & & & \\
\hline Infiltrative & $1.255(0.271-5.812)$ & & & \\
\hline $\begin{array}{l}\text { Systemic chemotherapy } \\
\text { (no/yes) }\end{array}$ & $2.486(0.712-8.681)$ & 0.153 & $\begin{array}{l}6.258(1.364- \\
28.713)\end{array}$ & 0.018 \\
\hline
\end{tabular}

HR, hazard ratio; CI, confidence interval; HBV, hepatitis B virus; HCV, hepatitis C virus; NBNC, non-B non-C virus 
Table 3. Predictive factors influencing progression free survival

\begin{tabular}{|c|c|c|c|c|}
\hline \multirow[b]{2}{*}{ Variables } & \multicolumn{2}{|l|}{ Univariate analysis } & \multicolumn{2}{|l|}{ Multivariate analysis } \\
\hline & $\mathrm{HR}(95 \% \mathrm{CI})$ & $p$-value & HR $(95 \% \mathrm{CI})$ & $\begin{array}{l}p- \\
\text { value }\end{array}$ \\
\hline Sex (male/female) & $0.311(0.073-1.328)$ & 0.115 & & \\
\hline Age & $0.980(0.942-1.020)$ & 0.980 & & \\
\hline ECOG $(0-1 / 2)$ & $2.703(0.351-20.810)$ & 0.602 & & \\
\hline BCLC (A-B/C) & $4.121(1.729-9.823)$ & 0.006 & $\begin{array}{l}3.530(1.070- \\
11.642)\end{array}$ & 0.001 \\
\hline Child-Pugh Class (A/B) & $1.167(0.465-2.933)$ & 0.742 & & \\
\hline Albumin & $1.327(0.640-2.751)$ & 0.448 & $2.637(0.962-7.228)$ & 0.059 \\
\hline Bilirubin & $1.549(0.874-2.745)$ & 0.134 & $2.639(1.165-5.978)$ & 0.020 \\
\hline Tumor size & $1.046(0.971-1.127)$ & 0.238 & & \\
\hline Alpha-fetoprotein & $1.000(1.000-1.000)$ & 0.112 & $1.000(1.000-1.000)$ & 0.019 \\
\hline Viral etiology & & 0.352 & & 0.098 \\
\hline $\mathrm{HBV}$ & 1 & & 1 & \\
\hline $\mathrm{HCV}$ & $1.763(0.590-5.272)$ & & $2.746(0.830-9.080)$ & \\
\hline NBNC & $0.633(0.214-1.874)$ & & $0.469(0.148-1.489)$ & \\
\hline Total dose & $1.000(0.999-1.000)$ & 0.185 & & \\
\hline PVT (no/yes) & $2.535(1.057-6.082)$ & 0.037 & & \\
\hline Tumor type & & 0.087 & & \\
\hline Nodular & 1 & & & \\
\hline Multinodular & $2.805(1.065-7.387)$ & & & \\
\hline infiltrative & $2.040(0.765-5.442)$ & & & \\
\hline $\begin{array}{l}\text { Systemic chemotherapy } \\
\text { (no/yes) }\end{array}$ & $2.476(1.102-5.564)$ & 0.023 & & \\
\hline
\end{tabular}
$\mathrm{HR}$, hazard ratio; $\mathrm{CI}$, confidence interval; $\mathrm{HBV}$, hepatitis B virus; $\mathrm{HCV}$, hepatitis $\mathrm{C}$ virus; $\mathrm{NBNC}$,
non-B non-C virus 
medRxiv preprint doi: https://doi.org/10.1101/2020.09.20.20197285; this version posted September 23, 2020. The copyright holder for this preprint (which was not certified by peer review) is the author/funder, who has granted medRxiv a license to display the preprint in perpetuity. All rights reserved. No reuse allowed without permission.

Table 4. Toxicities after RT

No. of patients (\%)

Grade $1 \quad$ Grade 2 Grade 3 Grade 4 Grade 5

Fatigue

Anorexia

Nausea/vomiting

Abdominal pain

Diarrhea

Hyperbilirubinemia

Thrombocytopenia
$4(10.0 \%)$

$2(5.0 \%)$

$4(10.0 \%)$

$9(22.5 \%) \quad 3(7.5 \%)$

$1(0.4 \%)$

$9(22.5 \%) \quad 7(17.5 \%)$

$10(25.0 \%) 11(27.5 \%) 2(5.0 \%)$

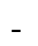

$-$

- 
Table 5. Selected previously published studies with correlating subjects

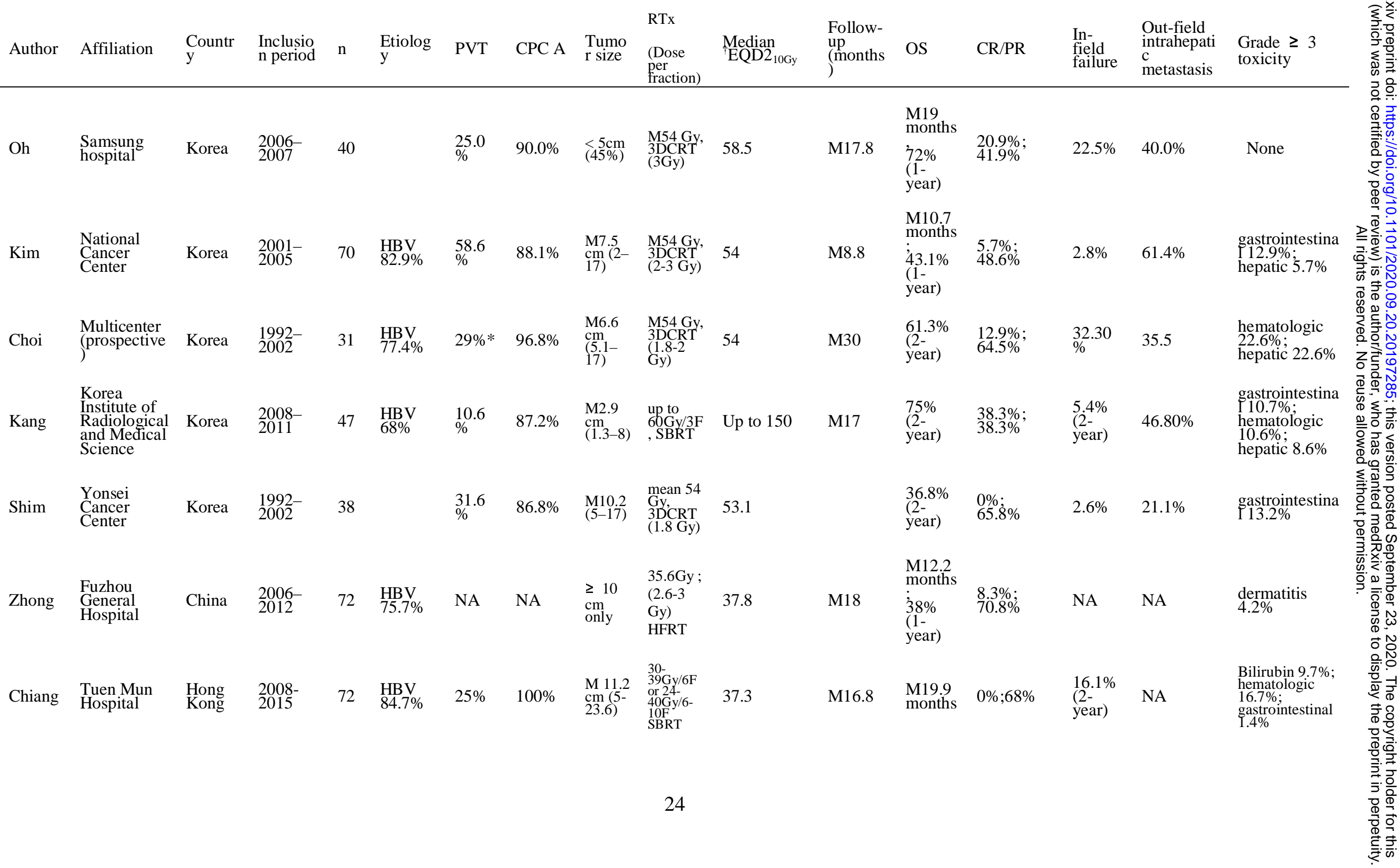




\begin{tabular}{|c|c|c|c|c|c|c|c|c|c|c|c|c|c|c|c|c|}
\hline Jacob & $\begin{array}{l}\text { Univ: of } \\
\text { Birmingham }\end{array}$ & US & $\begin{array}{l}2008- \\
2013\end{array}$ & 37 & $\begin{array}{l}\mathrm{HCV} \\
51.4 \% \\
\text { Alcohol } \\
18.9 \%\end{array}$ & 0 & $\begin{array}{l}\text { Mean } \\
\text { score } \\
6.3+/- \\
1.2\end{array}$ & $\begin{array}{l}\text { Mean } \\
6.1 \mathrm{~cm} \\
+/-2.4\end{array}$ & $\begin{array}{l}45 \mathrm{~Gy} / 3 \mathrm{~F}, \\
\text { SBRT }\end{array}$ & 93.8 & & $\begin{array}{l}\text { M33 } \\
\text { months; } \\
(67.6 \% \\
\text { at } 2- \\
\text { year })\end{array}$ & $\begin{array}{l}30.3 \% \\
57.6 \%\end{array}$ & $10.8 \%$ & NA & $\begin{array}{l}\text { gastrointestina } \\
12.7 \%\end{array}$ \\
\hline $\begin{array}{l}\text { Park } \\
\text { (presen } \\
\text { t study) }\end{array}$ & $\begin{array}{l}\text { Korea } \\
\text { University } \\
\text { Ansan } \\
\text { Hospital }\end{array}$ & Korea & $\begin{array}{l}2010- \\
2019\end{array}$ & 40 & $\begin{array}{l}\mathrm{HBV} \\
62.5 \% \\
\mathrm{NBNC} \\
22.5 \%\end{array}$ & $30 \%$ & $\begin{array}{l}77.50 \\
\%\end{array}$ & $\begin{array}{l}\text { M3.4 } \\
\text { cm } \\
(0.8- \\
20)\end{array}$ & M40 & $\begin{array}{l}47,8 \\
\text { (conventional } \\
57(\text { SBRT) }\end{array}$ & M14.4 & $\begin{array}{l}55.8 \% \\
\text { (2-year) }\end{array}$ & $\begin{array}{l}37 \% ; 41.3 \\
\%\end{array}$ & $\begin{array}{l}10.9 \% \\
\text { (2- } \\
\text { year) }\end{array}$ & $60 \%$ & $\underset{5 \%}{\text { hematologic }}$ \\
\hline
\end{tabular}

*Excludes main PVT

Equivalent dose in $2 \mathrm{~Gy}$ per fraction scheme with $\alpha / \beta$ ratio of 10

SBRT for residuals after RFA or surgery as well as TACE

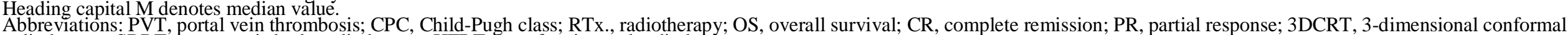
radiotherapy; SBRT, stereotactic body radiotherapy; HFRT, hypofractionated radiotherapy 
Figure 1. Kaplan-Meier Graph of overall survival (OS, progression free survival (PFS), local control rate (LCR), and intra-hepatic recurrence free survival (IHRFS)

Figure 2. Patterns of failure after radiation therapy

Figure 3.

Case 1 (patient no. 1, upper figures)

(A) This case involved a patient in her 40s, with HCC with hepatitis B and related cirrhosis. Liver magnetic resonance image (MRI) showed a $9.2 \mathrm{~cm}$-sized infiltrative tumor with PVT. (B) First, TACE was performed after diagnosis. Lipodol was compactly tagged in the right PVT, but incomplete TACE was performed on the remaining lesions. He underwent radiotherapy with 54 Gy in 27 fractions. (C) Followup imaging at 3 months after radiation therapy. The patient has achieved CR without any toxicity.

Case 2 (patient no. 2, lower figures)

(A) A main in his 50s, was diagnosed with hepatitis-B-related HCC. Liver dynamic CT showed a $13.4 \mathrm{~cm}$-sized huge viable $\mathrm{HCC}$ in hepatic segment 8. After two TACE treatments, there remained a persistent tumor in segment 8 . He underwent radiotherapy with 40 Gy in 16 fractions. (B) At follow-up imaging at 3 months, the longest diameter was reduced to $10.4 \mathrm{~cm}$, and consequent TACE affected more of the inside of the large tumor after radiotherapy. 


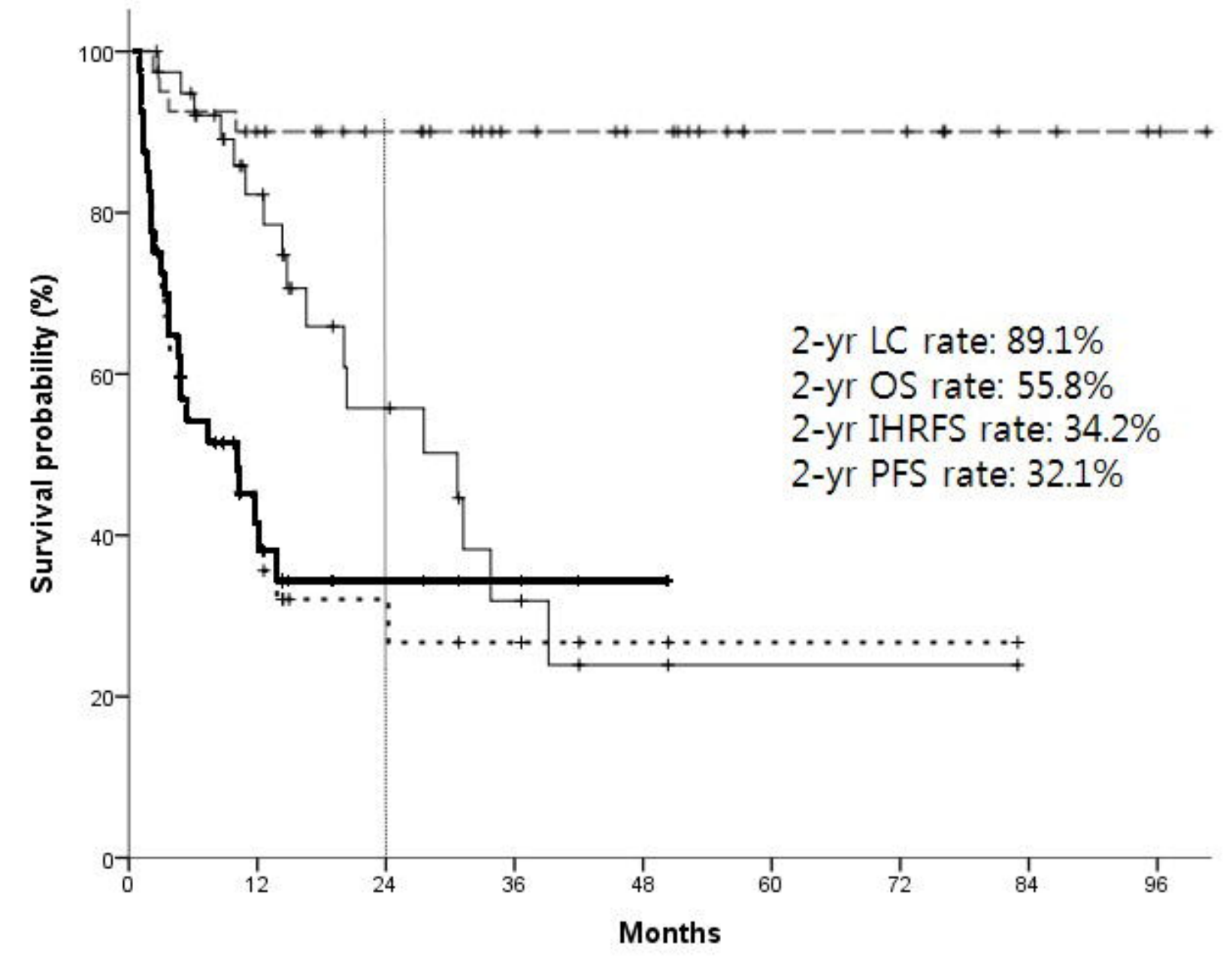




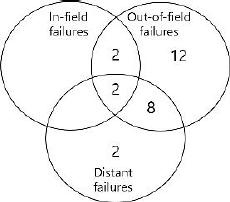



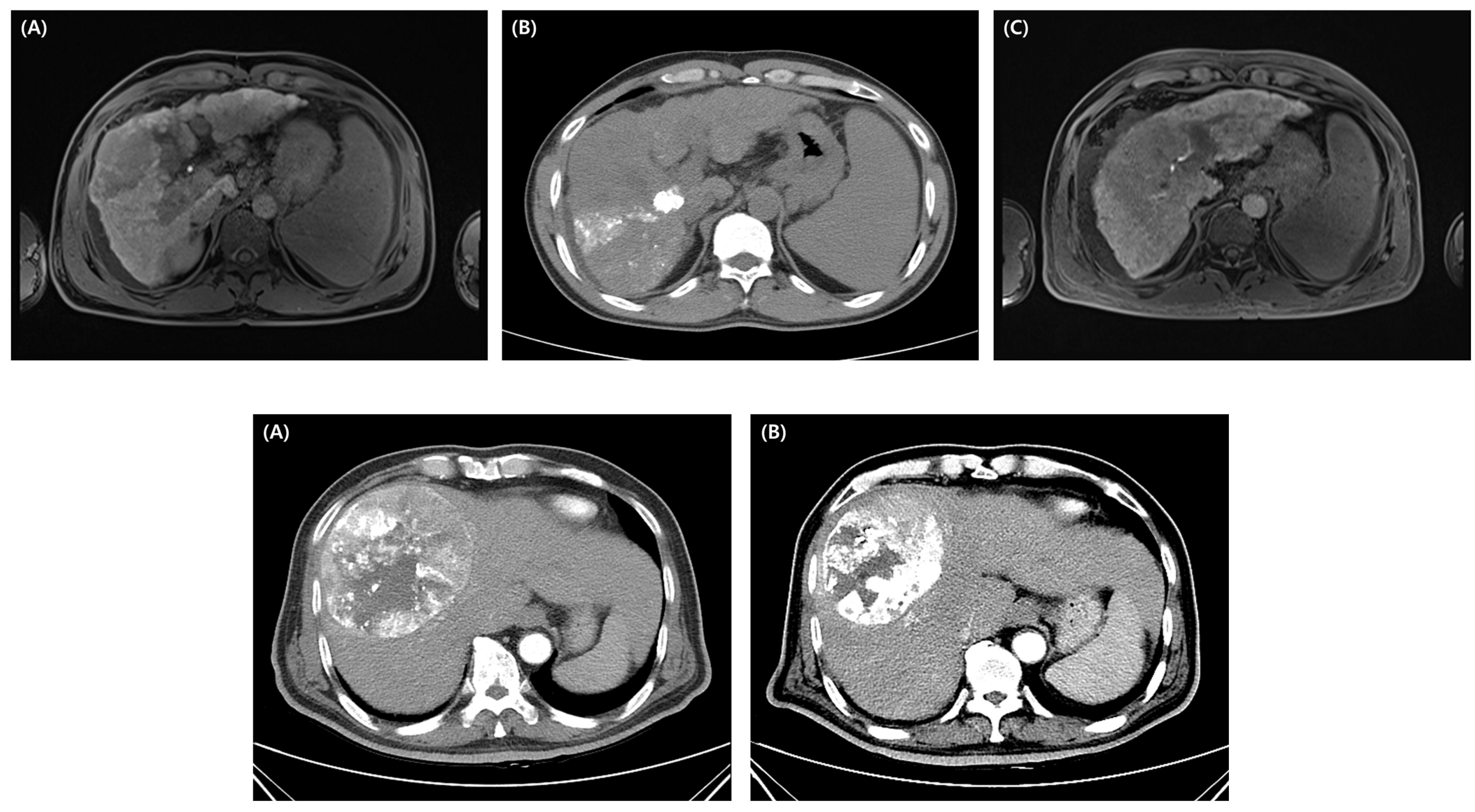